\title{
The influence of psychological capital and self-leadership strategies on job embeddedness in the banking industry
}

\begin{tabular}{|c|c|}
\hline \multicolumn{2}{|c|}{$\begin{array}{l}\text { Authors: } \\
\text { Martha Harunavamwe }{ }^{1} \\
\text { Daphne Pillay }{ }^{2} \\
\text { Petrus } \mathrm{Nel}^{3}\end{array}$} \\
\hline \multicolumn{2}{|c|}{$\begin{array}{l}\text { Affiliations: } \\
\text { 1Department of Industrial } \\
\text { Psychology, Faculty of } \\
\text { Economic and Management } \\
\text { Sciences, University of the } \\
\text { Free State, Bloemfontein, } \\
\text { South Africa }\end{array}$} \\
\hline \multicolumn{2}{|c|}{$\begin{array}{l}\text { 2Department of Human } \\
\text { Resource Management, } \\
\text { Faculty of Economic and } \\
\text { Management Science, } \\
\text { University of Pretoria, } \\
\text { Pretoria, South Africa }\end{array}$} \\
\hline \multicolumn{2}{|c|}{$\begin{array}{l}\text { 3epartment of Industrial } \\
\text { Psychology and People } \\
\text { Management, University of } \\
\text { Johannesburg, Johannesburg, } \\
\text { South Africa }\end{array}$} \\
\hline \multicolumn{2}{|c|}{$\begin{array}{l}\text { Corresponding author: } \\
\text { Martha Harunavamwe, } \\
\text { harunavamweM@ufs.ac.za }\end{array}$} \\
\hline \multicolumn{2}{|c|}{$\begin{array}{l}\text { Dates: } \\
\text { Received: } 30 \text { Dec. } 2019 \\
\text { Accepted: } 27 \text { May } 2020 \\
\text { Published: } 14 \text { July } 2020\end{array}$} \\
\hline \multicolumn{2}{|c|}{$\begin{array}{l}\text { How to cite this article: } \\
\text { Harunavamwe, M., Pillay, D., \& } \\
\text { Nel, P. (2020). The influence } \\
\text { of psychological capital and } \\
\text { self-leadership strategies on } \\
\text { job embeddedness in the } \\
\text { banking industry. SA Journal } \\
\text { of Human Resource } \\
\text { Management/SA Tydskrif vir } \\
\text { Menslikehulpbronbestuur, } \\
\text { 18(0), a1294. https://doi. } \\
\text { org/10.4102/sajhrm. } \\
\text { v18i0.1294 }\end{array}$} \\
\hline \multicolumn{2}{|l|}{ Read online: } \\
\hline 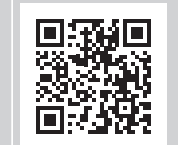 & $\begin{array}{l}\text { Scan this QR } \\
\text { code with your } \\
\text { smart phone or } \\
\text { mobile device } \\
\text { to read online. }\end{array}$ \\
\hline
\end{tabular}

Orientation: The success of organisations depends on their ability to appoint, develop, sustain and retain skilled employees. Retaining a strongly committed workforce has become a top priority for most organisations in the financial service sector. Nurturing positive organisational behaviours and emotions helps retain employees, and this is key to lowering the risk of losing precious talent.

Research purpose: The purpose of the study was to determine if self-leadership and psychological capital positively influence job embeddedness.

Motivation for the study: The study was motivated by the sentiments from a study conducted by Nafei (2015) that indicated that traditional methods of reducing turnover have become ineffective. The focus on positive retention was however described as promising.

Research approach/design and method: A cross-sectional quantitative survey was employed using self-administered questionnaires. The sample comprised 303 banking sector employees. Data were analysed using SmartPLS.

Main findings: Self-leadership strategies (constructive thought patterns, behavioural strategies and natural rewards) through psychological resources (hope, optimism and self-efficacy) positively influenced job embeddedness.

Practical/managerial implications: The banking industry that seeks to retain employees may invest in increasing levels of job embeddedness, which can be achieved through enhancing psychological resources and utilising self-leadership strategies.

Contribution/value add: The findings provide preliminary insights that contribute to the body of knowledge concerned with positive organisational behaviour and retention in the fields of industrial and organisational psychology in the South African context.

Keywords: psychological capital; job embeddedness; self-leadership; banking sector; organisational links; organisational fit; orgnaisational sacrifice; psychological resources; cognitive strategies; behaviroural strategies

\section{Introduction}

Organisations worldwide have invested billions of dollars and time to address turnover challenges. However, irrespective of all the efforts, businesses still struggle to retain talent (Biggane, Allen, Amis, Fugate, \& Steinbauer, 2017). The difficulties in attracting, sustaining and retaining qualified employees have become a painful reality. Because of a wide range of opportunities in the labour market, skilled employees find it difficult to attach themselves to one particular organisation (Akgunduz \& Cin, 2015). A total of 86\% of employers noted that attracting new skilled employees has become a nightmare, and $58 \%$ stated the difficulty associated with sustaining and convincing skilled employees to remain in the organisation for long, at the same time highlighting the high costs involved in hiring new employees (Biggane, Allen, \& Albert, 2016).

Accordingly, studies have been conducted on employee turnover (why people leave) (Zhao \& Liu, 2010), and evidence indicates that the turnover crisis in banks may be reduced by effectively exploring the concept of job embeddedness (JE) (why people stay) (Yavas, Babakus, \& Karatepe, 2008). Job embeddedness, a construct developed from a broader perspective in response to traditional turnover models (Moses \& Knutsen, 2012), investigates on-the-job and off-the-job

Copyright: (C) 2020. The Authors. Licensee: AOSIS. This work is licensed under the Creative Commons Attribution License. 
factors to determine why employees stay in their organisations. Management scholars presume that JE is beneficial for organisations because embedded employees are more loyal than less embedded individuals; they perform more effectively and engage in greater organisational citizenship behaviour (Biggane et al., 2016). It is therefore critical to explore the different methods that can be used to foster high levels of JE. Highly embedded individuals are less likely to be absent or engage in counterproductive work behaviours (Mallol, Holtom, \& Lee, 2007). Thus, instead of focussing directly on turnover intentions, organisations need to redirect their focus to JE that lowers the risk of losing precious talent and maintaining organisational effectiveness (Yao, Lee, Mitchell, Burton, \& Sablynski, 2004).

Considering the critical role of JE in employee retention and effective job performance, it is worth expanding the knowledge on the relevance of JE in the banking sector given that service delivery and service quality are crucial to the survival of banks (Yavas et al., 2008). Pokorny (2013) noted that about $71 \%$ of banking sector employees do not intend to stay with their companies until retirement. The banking and finance industry has one of the highest turnover rates among all industries (Mann \& Harter, 2016). Banks are currently on the lookout for individuals with new skill sets to match the rapidly changing nature of work in the industry; however, a recent study by Cole (2017) indicated that $48 \%$ of banking sector employees were actively searching for new opportunities, while 30\% of these employees have been working in the banks for less than a year (Cole, 2017). This implies that banks are losing newly hired critical talents. Massive retrenchments because of cost cutting and technological advancement have eliminated hundreds of jobs. This has diminished the public's trust in the banking sector and made it a less desirable workplace; banks have fallen out of favour as employers of choice for highly skilled individuals. No matter how advanced banking technology has become, the industry still needs motivated and talented employees to ensure sustainability and the success of the industry (Cole, 2017). The banking industry needs to realign retention practices with growing new technology and new banking systems to avoid the risk of losing precious talent (Salman, Ahmad \& Matin, 2014).

Exploring theories on JE opens a variety of avenues to develop strategies that may motivate employees to stay with an organisation, thus, widening the scope and depth of the existing literature (Sekiguchi, Burton, \& Sablynski, 2008; Zhao \& Liu, 2010). Following the traditional model of turnover, if employees are not satisfied with their jobs, they search for alternative employment and make comparisons with their current job. If they find that the alternative is better than their current job, they resign (Mann \& Harter, 2016). However, for contemporary organisations, being proactive and nurturing positive organisational behaviours (POBs) may assist in retaining employees. This is key to lowering the risk of losing precious talent (Bonner, 2016).
The current study seeks to investigate whether the expansion of personal resources may influence JE and foster retention. Although various studies have endeavoured to identify the factors related to employee retention (Biggane et al., 2016; Zhao \& Liu, 2010), assessing the influence of psychological capital (PsyCap) and self-leadership (SL) on JE may provide a wide range of strategies that might be instrumental in the retention of employees. Self-leadership strategies may develop psychological capacities, such as hope, self-efficacy and optimism (Neck \& Manz, 2010). In turn, individuals high in PsyCap are more adaptive in their jobs, have more harmonious relationships with their colleagues and have more friends and deeper organisational links; hence, they are more likely to stay longer at the organisation (Nafei, 2015).

It is indisputable that the organisational cost of leaving a job is extremely high, and the costs associated with recruitment and selection are massive. Therefore, banks are on the lookout for diverse techniques and strategies for retention (Salman et al., 2014). The prime challenge for the banking sector in South Africa is the retention of skilled employees who are adaptable to the changing nature of the work in the banks. Those who are technologically skilled, energetic and intelligent are always ready to switch whenever they are presented with new opportunities. In spite of the amount of effort invested in trying to understand 'why people leave', the challenge of high turnover rates of the skilled employees in the banks is still evident (Mann \& Harter, 2016). It is therefore necessary to investigate the extent to which a wide range of psychological resources may influence JE, bearing in mind that an individual's propensity to stay in the organisation depends upon many personal, organisational and environmental factors (Salman et al., 2014). Previous studies (Biggane et al., 2016; Bonner, 2016) have indicated that competitive companies have successfully managed to retain their employees and successfully kept precious talent longer by using a proactive approach and positive polices. This relates well to the recent theoretical extension of JE (Hom, Mitchell, Lee, \& Griffeth, 2012), which recognises that increasing psychological and personal resources of employees may effectively influence an employee's decision to stay or leave the organisation. Psychological capital and SL present a large number of psychological and personal resources (Kotze, 2018) that when combined, may assist individuals in the decision to either stay or leave the organisation. It is therefore valuable to investigate the combined influence of PsyCap and SL strategies on JE in the banking industry.

\section{Research purpose and objectives}

Based on the factors that may influence JE as identified by Salman et al. (2014), expanding both personal and psychological resources through SL strategies and PsyCap could be the mechanism through which JE can be fostered (Nafei, 2015). The purpose of the study was to determine if the positive aspects of SL and PsyCap influence JE of employees in the banking sector. The following objectives were addressed: 
- to determine the effect of PsyCap (hope, self-efficacy, resilience and optimism) on JE

- to establish the influence of SL strategies on JE

- to determine the mediating effect of PsyCap in the relationship between SL strategies and JE.

\section{Literature review}

Mitchell, Holtom, Lee, Sabalynski and Erez (2001) proposed the JE concept in an effort to improve the traditional employee turnover models that only modestly predicted turnover. Job embeddedness explains how a combination of different factors plays a role in influencing individuals' decisions to stay in a particular job (Mitchell et al., 2001). Rather than focussing on why employees leave the organisation, scholars shifted their attention to the new outlook, namely, to understand what motivates employees to stay (Lee, Mitchell, Sablynski, Burton, \& Holtom, 2004).

Job embeddedness is defined as on-the-job and off-the-job factors associated with individual links, fit and sacrifice (Mitchell et al., 2001). It refers to the collection of forces that influence employee retention, and emphasises all factors that keep an employee in the job, rather than the psychological process one goes through when quitting (Mitchell et al., 2001). This definition assumes that the more the organisational links, the better the organisational fit and the more the organisational sacrifices that need to be made, the more likely an employee will stay in a job. According to the JE theory for an employee to stay, his or her personal values, career goals and future plans must fit well with the larger corporate culture and the demands of his or her immediate job such as job knowledge, skills and abilities (Swider, Boswell, \& Zimmerman, 2011).

Organisational links refer to a number of threads that link an employee and his or her family to the social, psychological and financial web. This web may include the relationships an individual has with co-workers (Mitchell et al., 2001). Consistent with this, the social exchange theory indicates that relationships evolve over time into trusting, loyal and mutual commitments if the parties abide by certain 'rules' of exchange (Swider et al., 2011). When such relationships are strong, then they become very difficult to break; hence, individuals stay longer. Conversely, a person who has a job that is relatively isolated with few friends or connections to a project or people will experience less disruption in his or her web should he or she decide to leave (Hom et al., 2012). Sacrifice refers to what one may lose if one leaves the organisation. This may include perceived costs of material or psychological benefits, losing contact with colleagues, nonportable benefits, valuable projects and perks. The more one has to give up when leaving, the more difficult it is to discontinue employment with the organisation (Mitchell et al., 2001). Therefore, the theory postulates that JE refers to (1) individuals' links to other people, teams and groups in the organisation; (2) individual perceptions of fit with the job, organisation and community; and (3) the belief about what they would have to sacrifice if they were to leave their job.
Based on the above definition, JE can be viewed as a state of abundant resources (Halbesleben \& Wheeler, 2008). This aligns with Hobfoll's (2002) notion of a resource caravan. Based on that school of thought, the links component of JE represents person-to-person relationship resources (Mitchell et al., 2001). The fit component describes the sense of belonging that an employee feels with the job and the company. Then the sacrifice component relates directly to the primacy-of-loss tenet of the conservation of resources (COR) theory. Employees faced with the threat or actual loss of resources without replenishment are more likely to be motivated to protect and discretionally invest the remaining resources (Hobfoll, 2002). However, JE resources are restricted to the organisation and the position that one occupies; therefore, when an individual moves to another organisation, they cannot move the links with other people with them (Khandelwal \& Khanum, 2017). In addition, the perceived fit necessarily changes because of the new work environment (Hobfoll, 2002).

Job embeddedness is a strong predictor of a number of positive job outcomes, including employee attendance (Lev \& Koslowsky, 2012) and retention (Mallol et al., 2007) as compared to the well-known and accepted psychological explanations, such as job satisfaction and organisational commitment (Jiang, Liu, Mckay, Lee, \& Mitchell, 2012). Several studies show a positive relationship between JE and performance (Karatepe, 2016; Karatepe \& Karada, 2012; Nafei, 2015). Given the importance of JE in the organisations, improving personal resources can expand both links and fit. Resources, such as knowledge, friendship networks, time, physical stamina and a good relationship with a supervisor (Hobfoll, 2002) can positively influence both organisational fit and links, thereby increasing JE. Psychological capital dimensions and SL strategies present a pool of resources that employees may use to foster JE. Self-leadership strategies facilitate the development of psychological capacities (Kotze, 2018) while PsyCap, in turn, influences JE links and fit (Nafei, 2015).

\section{Psychological capital and job embeddedness}

Theoretically, PsyCap, and JE have their roots in POB. Thus, both positive psychology and positive retention embody a positive state and are crucial in modern businesses (Kotze, 2018). Contemporary organisations need to be proactive and provide skilled employees with a wide range of personal and psychological resources that may buffer the effects of leaving. Scholars and practitioners globally have embraced PsyCap and positivity beyond expectations. Psychological capital is a second-order, multi-dimensional construct and a latent variable, reflected by four psychological resource capacities (Luthans, Youssef, \& Avolio, 2015). It integrates the four positive psychological resources (hope, efficacy, resilience, optimism) that best fit the POB inclusion criteria (Luthans et al., 2015). These psychological resources function together and interact synergistically to produce differentiated manifestations over time and across contexts. They also share 
'the common theme of positive appraisal of circumstances and probability for success based on motivated effort and perseverance' (Luthans, Avolio, Avey, \& Norman, 2007, p. 550). Psychological capital emphasises the positive nature and strengths of individual employees and the role this has in fuelling their growth and work-related performance (Luthans, Avolio, Walumbwa, \& Li, 2005). Psychological capital is developed through a pattern of investment of psychic resources that result in obtaining experiential rewards from the present moment, while also increasing the likelihood of future benefits. It is about the state of components of one's inner life (Kalla, 2016).

From the perspective of psychological resources, individuals with high levels of PsyCap (hope, optimism, resilience and self-efficacy) are more likely to become embedded in their respective organisations because they enjoy more harmonious relationships with their colleagues, which enable them to experience high fit and deeper links with the organisation (Sun, Zhao, Yang, \& Fan, 2012). Leaving the organisation means loss of resources for such individuals, and according to the COR theory (Hobfoll, 2011), employees do not want to experience loss of resources. Nafei (2015) noted that the JE components, for example, organisational links and fit, can be expanded through PsyCap. A direct and exponentially influential relationship was found between psychological resources and JE components, with evidence even suggesting PsyCap as the original internal motivator for employees to stay in their jobs (Sun et al., 2012). Available evidence indicated that employees with higher PsyCap experience a higher level of organisational commitment and exhibit less turnover intentions (Avey, Luthans, \& Jensen, 2009). In a study by Sun et al. (2012), results show a statistically significant relationship between self-reported PsyCap, JE and performance, implying that improving the individual accumulated psychological state of employees would influence their retention intention.

Hypothesis 1: Psychological capital (hope, self-efficacy, resilience and optimism) has a positive influence on job embeddedness

\section{Self-leadership and job embeddedness}

Self-leadership empowers individuals to make decisions concerning their own tasks at work and implement them (Fletcher \& Kaüfer, 2003). This helps employees to experience autonomy, and they may stay longer in the organisation. Selfleadership is labelled as the discovery and maximising of self-potential (Manz \& Neck, 2004), a self-influence process through which people achieve the self-direction and selfmotivation needed to perform (Van Zyl, 2013). Neck and Houghton (2006) defined SL as a process through which individuals regulate and control their behaviour, influencing and leading themselves by using specific sets of behavioural and cognitive strategies. Individuals who use SL strategies enhance their personal effectiveness through behaviourfocussed, natural reward and constructive thought strategies (Breevaart, Bakker, Demerouti, \& Derks, 2016). Behaviourfocussed strategies refer to self-imposed strategies used to manage oneself in performing difficult, unattractive, but necessary tasks (Neck \& Manz, 2013). These strategies include self-observation, self-goal setting, self-reward, selfcorrecting feedback and practice (Van Zyl, 2013). Constructive thought patterns refer to the construction and maintenance of functional thinking patterns (Neck \& Houghton, 2006). These strategies involve creating and maintaining functional patterns of habitual positive ways of thinking and destroying destructive negative self-talk, replacing it with optimistic self-talk (Manz \& Neck, 2004). The natural reward strategies assist individuals to build pleasant and enjoyable features into their job activities, so that the tasks become naturally rewarding and enjoyable (Manz \& Neck, 2004). These strategies increase intrinsic motivation, self-determination and feelings of competence (Neck \& Manz, 2013).

The intentional behaviour that characterises the concept of SL includes self-awareness, self-goal setting, self-motivation and the ability to receive and act on feedback; all these contribute to understanding tasks and executing them well (Bryant \& Kazan, 2012). Therefore, initiating and maintaining SL are self-development activities that may influence organisational fit. Companies that encourage this reap the benefits of improved performance (Kotze, 2018). In addition to that, through natural rewards strategies, SL may directly influence organisational fit. This happens when individuals build more pleasurable aspects into their given tasks as well as shape their perceptions, so that the activities involved in the job itself become inherently rewarding (Lee \& Yom, 2015). This process increases intrinsic motivation, self-determination and feelings of competence (Neck \& Manz, 2013). In turn, individuals with intrinsic motivation, self-determination and feelings of competence experience the congruency between what they want to do or can do and what they are actually doing in their jobs; hence, they experience job and organisational fit (Mitchell et al., 2001). Therefore, when employees use the natural reward strategies to incorporate enjoyable features into their tasks, they eventually experience fit in the organisation. Well-fitting individuals stay longer with the organisation (Lee \& Yom, 2015).

Hypothesis 2: Self-leadership has a direct influence on job embeddedness.

\section{Self-leadership, psychological capital and job embeddedness}

As a way of moving towards the new positive organisation, individuals should self-lead. This involves examining individual thought patterns, which then facilitate the elimination of destructive thoughts and negative self-talk, and replacing them with more positive internal dialogues (Ram, 2015). Self-responsibility is at the centre of positivity and is the cardinal virtue necessary for all other virtues to develop (Khandelwal \& Khanum, 2017). The study therefore suggests SL as an entry point (at the individual level) that can be used to create a positive environment through PsyCap, which in turn encourages employees to stay longer with an organisation. 
Kotze (2018) noted that employees who implement SL strategies effectively enhance PsyCap; therefore, SL strategies facilitate the development of psychological capacities, which in turn expand the psychological resources of the workplace. The more resourceful the workplace is, the higher the chances that employees will stay (Khandelwal \& Khanum, 2017). A self-managing individual has the ability to control and successfully manipulate the resources to suit his or her own needs; therefore, self-leading individuals can positively influence the resourcefulness of the work environment and facilitate the mobilisation of internal resources (Harunavamwe \& Pillay, 2018). In relation to this, individuals who embody high levels of PsyCap can access more of their resources manifested through their cognitions, motivation, behaviour and social relationships and, in turn, increase the links and fit in JE (Sun et al., 2012).

Malinowski and Lim (2015) noted that, through SL, individuals discard automatic behavioural scripts and pursue novel and creative thoughts and actions, which result in an increase of social, psychological and physical resources. Organisations that use SL boost employee empowerment, encourage positivity and maximise performance (Khandelwal \& Khanum, 2017). Considerable evidence has been recorded in different domains on the relationship of positive psychology and positive thinking with satisfaction, productivity, performance, well-being and commitment (Martin, 2008). However, evidence on whether the employees with positive psychological characteristics are more attached to the organisation or more willing to be retained is unknown (Sun et al., 2012). Although a causal link between PsyCap and JE was established, SL seems to be instrumental in creating the conditions for positive thinking. It could be the mechanisms through which employees acquire psychological resources, which, in turn, influence JE.

In a recent diarised study, Bakker and Demerouti (2017) noted that SL strategies, such as constructive thought patterns and behaviour strategies, are used to expand the psychological resources and assist with increasing personal resources, such as optimism, self-efficacy and self-esteem. These psychological resources, in turn, influence JE (Nafei, 2015). It is also through SL strategies that the development of psychological capacities, such as hope, self-efficacy and optimism, are facilitated by recognising and replacing negative dysfunctional beliefs and assumptions with positive beliefs (Neck \& Manz, 2010). Kotze (2018) indicated that SL is a strong determinant of PsyCap, having a statistically significant positive influence on PsyCap dimensions. Self-leadership, along with self-efficacy and goal setting, facilitate the mobilisation of internal resources and form part of an iterative process of self-regulation in the positive behavioural change process (Manz, 2015).

Given the benefits associated with psychological resources and SL strategies, the current research endeavours to determine their relevance within the JE framework. Selfleadership strategies are part of the positive emotions and relevant personal resources within the workplace that lay the foundation of positivity (Kotze, 2018). The constructive thought patterns, for example, can increase and strengthen an individual's belief that they have what it takes to succeed (fit) and help them to remain hopeful and optimistic in their capabilities. Thus, SL strategies can be used as building blocks for expanding psychological resources. The psychological resources then influence JE. For the purpose of the study, the mediating role of PsyCap in the relationship between SL and JE was explored.

Hypothesis 3: Psychological capital mediates the relationship between self-leadership strategies and job embeddedness

\section{Research design Research method and approach}

The empirical aspect of the study used a cross-sectional survey design to collect quantitative primary data from the respondents by using self-report questionnaires to achieve the objectives of the study. A quantitative research framework was adopted because of its systematic and scientific nature of investigating data and their relationships (Hair, Celsi, Ortinau, \& Bush, 2008). A cross-sectional design with a survey data-collection technique was used to address the research questions. The survey research method was used because it is more appropriate for descriptive purposes and chiefly used in studies that have individual people as the units of analysis (Babbie \& Mouton, 2015).

\section{Research participants}

The study sought to obtain basic data and trends on the three constructs. Because of the strict regulations in the banking sector, it was difficult to get access to the sampling frame; therefore, convenience sampling was used to select 422 respondents working in different banks within the Free State province. Because of incomplete surveys and nonresponsiveness, only 303 questionnaires were used for the purpose of data analysis. The majority of the sample identified themselves as being African (57\%). More females (59\%) participated as compared to males. In terms of age, the majority of the respondents were aged between 26 and 30 years (31\%). In terms of education, the majority of employees have a diploma qualification (41\%). Further to this, the largest proportion of the respondents was operational-level employees (43\%).

\section{Measuring instruments}

The survey consisted of demographic questions, and three were scales used to measure the variables under investigation. These scales are discussed in the following sections.

JE: Mitchell and his colleagues (2001) developed the Job Embeddedness Scale (JES), which was used in the present study to operationalise the dependent variable. This measure consists of three sub-dimensions (organisational links, organisational fit and organisational sacrifice). 
SL: The Revised Self-Leadership Questionnaire (RSLQ) provided information on respondents' levels of SL. The RSLQ consists of items that are scored using a 5-point Likert scale (Houghton, Dawley, \& DiLiello, 2012).

PsyCap: The PsyCap Questionnaire (PCQ-24) containing the four subscales of PsyCap (self-efficacy, hope, optimism and resilience) was used to measure PsyCap. The PCQ-24 is a 24item scale that is scored using a 6-point Likert scale (Luthans et al., 2007).

\section{Research procedure and ethical considerations}

Ethical clearance was applied for and granted by the research ethics committee of the Faculty of Economic and Management Sciences. Potential participants were informed of their right to voluntary participation as well as ensuring anonymity of their responses. In addition, research participants could withdraw at any time during the data-collection process without any consequences. In instances where management would request feedback, both individuals and the organisation were informed that only aggregated data and results would be shared.

\section{Statistical analysis}

Cronbach's coefficient alpha was used to estimate the reliabilities associated with each of the measuring instruments and their associated sub-dimensions (where applicable). When conducting exploratory research, reliability estimates as low as 0.6 are deemed as acceptable (Hair et al., 2008).

Pearson's Product Moment Correlation provided evidence of the relationship between the independent variables (SL, PsyCap) and JE.

The different hypotheses were evaluated using the variancebased approach to structural equation modelling. The two families of Structural Equation Modelling included the covariance-based techniques and the variance-based techniques in which partial least squares (PLS) path modelling is the most prominent representative (Henseler, Ringle, \& Sinkovics, 2009). Covariance-based structural equation modelling assumes that one's data are normally distributed, and that the sample is quite big. In addition, it is predominantly used to test theory (Henseler et al., 2009). In contrast, variance-based structural equation modelling does not have the same strict assumptions associated with the data being used to evaluate a model (e.g. minimum sample size and normal distribution). Variance-based structural equation modelling is often used to evaluate complex models and the development of new theory (Henseler et al., 2009). Thus, for exploratory work in behavioural research fields, Lowry and Gaskin (2014) advised that the PLS may be selected, as it could provide distinctive theoretical insights. Therefore, in the current study, the proposed model was tested using the variance-based structural equation-modelling program, SmartPLS (Ringle, Wende, \& Becker, 2015). The PLS path modelling was deemed appropriate because it is suitable for prediction-oriented research and is recommended when testing and validating exploratory models. This approach suggests a two-step process to be followed when interpreting the results from both the outer (i.e., measurement) and inner (i.e., structural) models (Henseler et al., 2009). The outer model provides information as to the quality of the measures (and indicators) used to operationalise each of the constructs in the model. In terms of quality criteria, the outer model will be deemed as acceptable (in terms of both reliability and validity) when composite reliabilities are 0.7 and higher, with values of 0.5 and higher for the average variance extracted (AVE). In addition, the outer model requires each of the indicators used to operationalise the constructs to have statistically significant loadings associated with each of the latent variables. In contrast, the inner model provides information as to both the strength (beta) and statistical significance ( $p$-values) of the proposed paths in the theoretical model. Finally, the R-square value provides an indication as to the predictive power of the theoretical model (Henseler et al., 2009). SmartPLS version 3 was used to evaluate all three hypotheses.

It should be noted that the present study employed item parcels (composite scores of the sub-dimensions of jobembeddedness and PsyCap, and a composite score for SL) to reduce the complexity of the outer model to be estimated. It would not have been advisable to use all the items, thus increasing the complexity of the model and the number of parameters to be estimated (Hair et al., 2008).

\section{Results}

The reliability estimates for each variable are reported in Table 1.

Table 1 shows that all variables have acceptable levels of reliability, ranging between 0.74 (natural reward strategies) and $0.93(\mathrm{JE})$.

Table 2 shows the descriptive statistics and the correlations between JE and the sub-dimensions of PsyCap. The table also shows the correlations between JE and sub-dimensions of SL.

From Table 2, it is clear that all the dimensions of PsyCap and the SL strategies have statistically significant correlations with JE. Optimism $(r=0.44)$ and behavioural strategies

TABLE 1: Reliability estimates for the psychological capital, self-leadership and job embeddedness scale $(N=303)$.

\begin{tabular}{lc}
\hline Variable & Cronbach's $\alpha$ \\
\hline 1. JE & 0.934 \\
2. PsyCap & 0.946 \\
Self-efficacy & 0.910 \\
Hope & 0.889 \\
Resilience & 0.810 \\
Optimism & 0.772 \\
3. SL & 0.939 \\
Behavioural strategies & 0.897 \\
Cognitive strategies & 0.886 \\
Natural rewards & 0.739 \\
\hline
\end{tabular}

JE, job embeddedness; PsyCap, psychological capital; SL, self-leadership. 
TABLE 2: Descriptive statistics, correlations between the variables $(N=303)$.

\begin{tabular}{|c|c|c|c|c|c|c|c|c|c|}
\hline Variable & Mean & SD & 1 & 2 & 3 & 4 & 5 & 6 & 7 \\
\hline 1. Job embeddedness & 10.225 & 1.654 & - & - & - & - & - & - & - \\
\hline 2. Self-efficacy & 4.12 & 0.92 & $0.415^{*}$ & - & - & - & - & - & - \\
\hline 3. Hope & 4.20 & 0.84 & $0.407^{*}$ & $0.733^{*}$ & - & - & - & - & - \\
\hline 4. Resilience & 4.08 & 0.72 & $0.409 *$ & $0.638^{*}$ & $0.677^{*}$ & - & - & - & - \\
\hline 5. Optimism & 4.00 & 0.71 & $0.441^{*}$ & $0.699 *$ & $0.745^{*}$ & $0.704 *$ & - & - & - \\
\hline 6. Behavioural strategies & 3.67 & 0.73 & $0.415^{*}$ & $0.659 *$ & $0.738^{*}$ & $0.630 *$ & $0.711 *$ & - & - \\
\hline 7. Cognitive strategies & 3.71 & 0.74 & $0.396 *$ & $0.604 *$ & $0.676^{*}$ & $0.607^{*}$ & $0.693 *$ & $0.771 *$ & - \\
\hline 8. Natural rewards & 3.75 & 0.78 & $0.387 *$ & $0.574 *$ & $0.610 *$ & $0.577^{*}$ & $0.562 *$ & $0.648 *$ & $0.653 *$ \\
\hline
\end{tabular}

3.75

0.78

$0.387 *$

$0.574^{*}$

$*, p \leq 0.001$

TABLE 3: Descriptive statistics, correlations between job embeddedness and psychological capital and self-leadership $(N=303)$.

\begin{tabular}{lccccc}
\hline Variable & Mean & SD & $\mathbf{1}$ & $\mathbf{2}$ & $\mathbf{3}$ \\
\hline 1. JE & 10.225 & 1.654 & - & - & - \\
2. PsyCap & 16.404 & 2.811 & $0.474^{*}$ & - & - \\
3. SL & 11.130 & 2.006 & $0.448^{*}$ & $0.810^{*}$ & - \\
\hline
\end{tabular}

$\mathrm{JE}$, job embeddedness; PsyCap, psychological capital; SL, self-leadership; SD, standard deviation $*, p \leq 0.001$.

TABLE 4: Quality criteria (outer model).

\begin{tabular}{lcc}
\hline Variable & Composite reliability & AVE \\
\hline JE & 0.868 & 0.692 \\
PsyCap & 0.932 & 0.775 \\
SL & 0.921 & 0.794 \\
\hline
\end{tabular}

$\mathrm{JE}$, job embeddedness; AVE, average variance extracted.

TABLE 5: Outer loadings.

\begin{tabular}{lccc}
\hline Variable & Factor loading & $\boldsymbol{t}$ & $\boldsymbol{p}$ \\
\hline Behavioural strategies: SL & 0.913 & 94.145 & $0.000^{*}$ \\
Cognitive strategies: SL & 0.910 & 73.587 & $0.000^{*}$ \\
Hope: PsyCap & 0.900 & 81.685 & $0.000^{*}$ \\
Natural rewards: SL & 0.849 & 44.22 & $0.000^{*}$ \\
Optimism: PsyCap & 0.897 & 74.929 & $0.000^{*}$ \\
Organisational fit: JE & 0.913 & 83.334 & $0.000^{*}$ \\
Organisational links: JE & 0.699 & 15.361 & $0.000^{*}$ \\
Organisational sacrifice: JE & 0.865 & 41.403 & $0.000^{*}$ \\
Resilience: PsyCap & 0.854 & 48.778 & $0.000^{*}$ \\
Self-efficacy: PsyCap & 0.870 & 52.848 & $0.000^{*}$ \\
\hline
\end{tabular}

JE, job embeddedness; PsyCap, psychological capital; SL, self-leadership. $*, p \leq 0.001$.

$(r=0.42)$ have the strongest relationship with JE. Natural reward strategies $(r=0.39)$ have the weakest relationship with JE.

Table 3 shows the descriptive statistics and the correlations between the composite scores for JE and PsyCap. The table also shows the correlations between the composite scores for JE and SL.

From Table 3, it is clear that all the independent variables (SL and PsyCap) have statistically significant correlations with JE. Psychological capital $(r=0.47)$ has the strongest relationship with JE. Self-leadership has a statistically significant correlation with JE $(r=0.45)$ but not as strong as PsyCap.

Table 4 shows composite reliabilities for the three variables and the convergent validity assessed using the AVE.
TABLE 6: Path coefficients (inner model)

\begin{tabular}{lccc}
\hline Variables & beta & $\boldsymbol{t}$ & $\boldsymbol{p}$ \\
\hline PsyCap $\geq \mathrm{JE}$ & 0.355 & 3.754 & $0.000^{* *}$ \\
$\mathrm{SL} \geq \mathrm{JE}$ & 0.222 & 2.456 & $0.014^{*}$ \\
$\mathrm{SL} \geq$ PsyCap & 0.815 & 38.111 & $0.000^{* *}$ \\
\hline
\end{tabular}

$\mathrm{JE}$, job embeddedness; PsyCap, psychological capital; SL, self-leadership. $*, p<0.05 ; * *, p \leq 0.001$.

TABLE 7: Specific indirect effects.

\begin{tabular}{lccc}
\hline Variable & Indirect effects & $\boldsymbol{t}$ & $\boldsymbol{p}$ \\
\hline $\mathrm{SL} \geq$ PsyCap $\geq \mathrm{JE}$ & 0.289 & 3.462 & $0.001^{*}$ \\
\hline
\end{tabular}

JE, job embeddedness; PsyCap, psychological capital; SL, self-leadership.

$*, p \leq 0.001$.

It is evident from Table 4 that all the indicators had acceptable composite reliabilities and sufficient convergent validity; both composite reliability and AVE values are higher than 0.5 .

Table 5 shows the outer loadings for the indicators of variables.

Table 5 indicates that all the indicators have statistically significant loadings on their respective latent variables, hence meeting the required quality criteria.

Table 6 shows the size and significance of the proposed paths.

Table 6 presents the results associated with the size and significance of the proposed paths (i.e. quality criteria associated with the inner model). It is clear that all proposed paths are statistically significant, with $p<0.05$. This proposed model explained $30 \%$ of the variance in employees' levels of JE, which can be explained as moderate. It should be noted that both PsyCap $(\beta=0.355)$ and SL $(\beta=0.222)$ have significant relationships (i.e. paths) with JE. These results provide support for both Hypotheses 1 and 2.

To determine whether PsyCap mediates the relationship between SL and JE, the specific indirect effects (Table 7) should be consulted. Table 7 depicts the indirect effect of SL on JE.

From Table 7, it is evident that the mechanism through which SL influences JE (via PsyCap) is positive (Indirect effect [IE] = $0.289)$ and statistically significant $(p=0.001)$. Although the mediating effect is significant, the result points to partial 
mediation because of the fact that the direct path between SL and JE is still statistically significant. Hence, the study found partial support for Hypothesis 3.

\section{Discussion}

Studies on talent management have indicated that an organisation that is able to retain its human capital has a significant advantage over its competitors. This suggests that investing in mechanisms that can promote JE is crucial for organisational success because JE is known to predict turnover intention (Holtom \& Darabi, 2018; Coetzer, Inma, \& Poisat, 2017). As emphasised earlier, JE is characterised by three elements, that is, personal links with the organisation and people within the organisation; a sense of congruence between personal attributes and the demands of the job; and finally, a reluctance to lose the relationships and resources that have been established within or because of the organisation (Mitchell et al., 2001). These elements, that is, links, fit and sacrifice, are viewed as resources that promote embeddedness in one's job. Consistent with the COR theory, employees are encouraged by the need to acquire and protect resources, or those aspects they attach personal value to, that is, links, fit and sacrifice (Sun et al., 2012). Using this argument as a point of departure, the current study has framed both PsyCap and SL as mechanisms that facilitate the key constructs of JE, that is, links, fit and sacrifice. Therefore, the primary aim of the study was to investigate the role of both PsyCap and SL in influencing the levels of JE and the role of PsyCap in mediating the relationship between SL and JE.

As indicated by the results, there was a significant relationship between PsyCap and JE, which provides support for Hypothesis 1. These results are consistent with those of Sun et al. (2012) who found a statistically meaningful association between self-reported PsyCap and JE. Results of the current study also support the findings of Rego, Sousa, Marques and eCunha (2012), who found that the dimensions of PsyCap (hope, optimism, resilience and self-efficacy) show a positive relationship with JE (fit, links and sacrifice), and employees with higher PsyCap are likely to experience higher levels of embeddedness, because they have a large support network in their current organisations (links). Nafei (2015) confirmed the findings of Rego et al. (2012), indicating that in his study, the availability of higher levels of PsyCap was positively related to the quality of the relationship that links employees and supervisors at work, which, in turn, led to an improvement in the level of JE, and a reduction of negative reactions in the work environment. Sun et al. (2012) stated that employees manifesting psychological resources, such as hope, optimism, resilience and self-efficacy, are more adaptive to their jobs, have more harmonious relationships with their colleagues and have deeper links in the organisation. Hence, these employees are more likely to have access to a wide range of job resources that will then facilitate JE. Fredrickson (2001) theorised that positive emotions or traits have the ability to broaden the employee's thought action response pattern, which encourages the pursuit of a wider range of thoughts and actions than usual. Because PsyCap consists of four positive traits, that is, hope, optimism, self-efficacy and resilience; these traits have the ability to broaden thoughts and actions, which encourages positive adaptation to the organisational environment. This allows the individual to successfully adapt to his or her work environment, which enhances the level of job fit. By experiencing a sense of congruence between personal attributes and the demands of the job, the individual is less likely to leave the organisation.

Hypothesis 2 proposed in the current study is supported based on the findings, which indicated a significant relationship between SL and JE. This is consistent with the work of Khandelwal and Khanum (2017) who reported that there are several pathways through which dimensions of SL can work to influence the extent to which one is embedded in the job. They further indicate that when the employee is driven and rewarded by inherently pleasurable features of the task or activities they perform (natural rewards), that process creates feelings of competence (fit). The employees begin to believe that their personal attributes, that is, skills and abilities, are congruent with what is required for good job performance (fit), and this belief subsequently strengthens JE. This suggests that one pathway through which SL may work to influence JE is through natural rewards, which works to positively strengthen beliefs of organisational fit (Khandelwal \& Khanum, 2017). In addition, Bryant and Kazan (2012) argued that SL is an effective mechanism that can be used to promote active, empowered employees who proactively shape and influence their organisational settings. This is done through employees creating novel standards and effective procedures by applying constructive thought patterns. Neck and Houghton (2006) maintained that adopting constructive thought patterns allows for the construction and maintenance of functional thinking patterns. These functional thinking patterns emphasise the importance of establishing organisational links that support the employee and contribute to effective work behaviour. The employee begins to understand the role of relationships within the workplace and the role relationships may play in facilitating career success. As a result, through applying characteristics of SL, an employee becomes more embedded within his or her job.

While results of the current study support the mediating effect of PsyCap on the relationship between SL and JE, it was found that the direct relationship between SL and JE was still statistically significant in the presence of PsyCap, indicating a partial mediation. Results also suggest that although SL has the ability to independently influence JE, the influence of SL on JE may be heightened in the presence of PsyCap. This is because the relationship between SL, PsyCap and JE appears to be stronger than the direct relationship between SL and JE. Neck and Manz (2010) stated that by implementing SL strategies, such as constructive thought patterns and behavioural strategies, psychological strengths, such as hope, 
self-efficacy and optimism are facilitated, as employees begin to identify and replace negative dysfunctional beliefs and assumptions with positive beliefs. These positive thought patterns allow for career-enhancing behaviours, such as establishing organisational links and fit between personal strengths and organisational requirements. According to Neck and Houghton (2006), by adopting constructive thought patterns, the employee's belief in his or her ability (selfefficacy) to forge organisational links and adapt personal attributes to meet the job requirements is enhanced. This implies that having an elevated level of self-efficacy influences the establishment of organisational links and fit, explaining how constructive thought patterns, through selfefficacy, can influence JE. This suggests that, whilst adopting constructive thought patterns may encourage the establishment of organisational relationships and fit, the presence of the psychological resources such as self-efficacy may strengthen the motivation to establish these relationships.

A similar argument can be used to explain the role of selfefficacy in mediating the effect of behavioural strategies on organisational links and fit. Behavioural strategies involve self-goal setting, self-observation and self-punishment, together with self-reward (Van Zyl et al., 2016). These strategies emphasise explicit behaviours that are required to be altered, reinforced or even eliminated for the sake of success, which is an essential first step towards behavioural modification (Manz \& Neck, 2004). Behavioural strategies can be achieved through the nurturing of self-efficacy, as the ability to regulate these strategies strengthens one's belief in his or her ability to accomplish a goal. This belief in turn motivates the employee to establish positive organisational links and adjust behaviour to fit the organisation. This suggests that whilst behavioural strategies emphasise the importance of establishing organisational links and fit, selfefficacy enhances employee's sense of control over tasks they perform and their commitment to goals. Thus, through behavioural strategies, it becomes easier for individuals to effectively set behaviour-altering goals to achieve self-efficacy and improve themselves (Neck \& Manz, 2013). In turn, selfefficacy, as a motivational variable, regulates individual objectives, reflections, efforts, coping strategies and levels of tenacity. Thus, self-efficacious individuals (the belief that 'I can do it') possess high levels of confidence and that confidence gives them the energy to persist in the establishment of organisational links and fit (Yakin \& Erdil, 2012).

Whilst the role of natural rewards in promoting organisational fit has been established, literature indicates that optimism can serve to mediate the effect of natural rewards on organisational fit through the notion of positive expectancies. According to Lee and Yom (2015), when an employee begins to incorporate more enjoyable aspects into their given tasks and shape their perceptions, so that the activities involved in the job itself become inherently rewarding, a sense of intrinsic motivation, self-determination and feeling of competence begins to develop (Neck \& Manz, 2013). Employees with intrinsic motivation, self-determination and feelings of competence experience the congruency between what they want to do or can do and what they are actually doing in their jobs; hence, they experience job and organisational fit (Mitchell et al., 2001). Luthans et al. (2005) argued that optimism is a resource that helps employees to preserve their interest even in the face of low internal resources such as intrinsic motivation and self-determination. This suggests that, even in situations in which the individual does not develop intrinsic motivation through natural rewards, the presence of optimism can mitigate the lack of motivation and self-determination to ensure that a level of organisational fit is still obtained. Thus, SL, through optimism, helps employees to preserve their feelings of competence, which influence levels of fit. As a result, it can be concluded that, whilst SL influences JE, the presence of psychological strengths found in PsyCap can mitigate the outcome of the relationship between the two variables.

\section{Practical implications}

Findings of the current study indicate that employees who are hopeful, self-efficacious, optimistic and resilient, and who experience high levels of SL, offer organisations a competitive advantage, as they tend to be embedded within their jobs. The results suggest that SL and PsyCap positively influence JE. This implies that organisations that need to retain employees must invest in combining SL strategies and psychological resources, as these are expected to have a positive impact on JE. Organisations can strengthen the behavioural strategies aspect of SL through facilitating activities that encourage goal setting, self-reward, selfobservation and self-cueing. An effective way of doing this is through the use of coaching and mentoring in which staff members are assisted in setting achievable goals, which, in turn, facilitate hope and optimism. Organisations can facilitate the constructive thought pattern dimension of SL through the provision of cognitive behavioural therapy by a registered psychologist. Because constructive thought patterns consist of construction and maintenance of functional thinking patterns, the psychologist can work with employees to facilitate positive self-talk (i.e. what people covertly tell themselves) and equip employees with strategies on how to identify and replace negative and destructive selftalk with more positive internal dialogues. In addition, organisations can facilitate the natural rewards aspect of SL through creating pleasant and enjoyable features into employee's job activities, so that the tasks become naturally rewarding and enjoyable. This can be done through job enrichment in which the organisation adds greater responsibility and additional tasks that serve to stimulate the employee. Organisations can consider creating opportunities for learning new skills and aligning tasks to the employee's personal values. These aspects are expected to increase the natural rewards the job provides.

Results of the current study also support the role of PsyCap in influencing JE. It is therefore crucial that organisations in the banking sector recognise the importance of PsyCap and invest in training programmes that assist employees to 
develop and maintain high levels of PsyCap. Organisations can consider the application of micro-interventions designed to facilitate PsyCap (Luthans et al., 2005). These interventions emphasise a three-pronged approach revolving around a goal-oriented framework, which includes goal design, pathway generation and overcoming obstacles. In addition, Paek, Schuckert, Kim and Lee (2015) advocated for PsyCap development programmes that target employees at group or organisational levels, because social capital, such as coworker support, adds value and increases POBs. These interventions could take the form of team-building interventions that incorporate activities that focus on building self-efficacy, resilience, hope and optimism. While attempting to strengthen PsyCap among hired employees is crucial, organisations can also consider emphasising the importance of PsyCap in the recruitment process (Paek et al., 2015). This can be done through using a valid and reliable psychometric instrument to measure the levels of PsyCap of new employees. Organisations will then be able to identify employees that require specific attention in terms of developing their levels of PsyCap. The above initiatives may contribute in ensuring that skilled employees stay longer in their respective organisations.

\section{Limitations and prospects for future research}

The current study explored the role of JE, SL and PsyCap amongst employees in the banking sector. A significant limitation was the lack of empirical evidence addressing JE and SL, specifically in the banking sector. It was therefore difficult to compare the empirical results obtained on the relationship between JE and SL with previous literature. However, as indicated in the discussion, results obtained in the current study were consistent with the limited studies on JE and SL, which indicated that the findings were reliable.

In addition, the focus on employees in the banking sector implies that the findings of the current study must be applied with caution when considering other samples. Future researchers are encouraged to explore the combination of JE, SL and PsyCap in different samples to determine if similar results are found.

Although the measures used in the current study were considered adequate to measure each construct, the use of self-report measures could cause common method bias because of the possibility of subjective interpretations from participants. However, the common method bias could not be the source of observed relationships in the current study, as most of the reported correlations were in line with previous published findings.

Finally, the current study employed a cross-sectional method that posed challenges when trying to assess the causal nature of the relationships, as no conclusions could be made regarding the long-term effectiveness of SL and PsyCap in predicting JE. Future studies are encouraged to employ a longitudinal design to assess the long-term effect of PsyCap and SL on JE.

\section{Conclusion}

Findings of the current study provide insights into the importance of JE in financial institutions and the role that PsyCap and SL may play in influencing employee's levels of JE. From the findings, it can be concluded that PsyCap resources, which include hope, resilience, optimism and selfefficacy, partially mediate the effects of SL strategies such as constructive thought patterns, natural rewards and behavioural strategies on JE. As a way forward, financial institutions are urged to investigate SL and PsyCap resources in relation to each other. However, in cases where levels of SL may be low, organisations should consider enhancing existing PsyCap resources, as the empirical findings suggested that these resources could partially mediate the effect of SL on JE.

\section{Acknowledgements}

\section{Competing interests}

The authors have declared that no competing interests exist.

\section{Authors' contributions}

All authors contributed equally to this work.

\section{Funding information}

This research received no specific grant from any funding agency in the public, commercial or not-for-profit sectors.

\section{Data availability statement}

Data for this article are available upon request.

\section{Disclaimer}

The views and opinions expressed in this article are those of the authors and do not necessarily reflect the official policy or position of any affiliated agency of the authors.

\section{References}

Akgunduz, Y., \& Cin, F.M. (2015). Job embeddedness as a moderator of the effect of manager trust and distributive justice on turnover intentions. Anatolia, 26(4), 549-562. https://doi.org/10.1080/13032917.2015.1020504

Avey, J.B., Luthans, F., \& Jensen, S.M. (2009). Psychological capital: A positive resource for combating employee stress and turnover. Human Resource Management, 48(5), 677-693. https://doi.org/10.1002/hrm.20294

Babbie, E., \& Mouton, J. (2015). The practice of social research. Oxford: Oxford University Press.

Bakker, A.B., \& Demerouti, E. (2017). Job demands - Resources theory: Taking stock and looking forward. Journal of Occupational Health Psychology, 22(3), 273. https://doi.org/10.1037/ocp0000056

Biggane, J.E., Allen, D.G., \& Albert, L.S. (2016). The role of positive illusions in employment relationships. Human Resource Management Review, 26(3), 270-281. https://doi.org/10.1016/j.hrmr.2016.03.003

Biggane, J.E., Allen, D.G., Amis, J., Fugate, M., \& Steinbauer, R. (2017). Cognitive appraisal as a mechanism linking negative organizational shocks and intentions to leave. Journal of Change Management, 17(3), 203-227. https://doi.org/10.1080/ 14697017.2016.1219379

Bonner, J.M. (2016). My boss is morally disengaged: The role of ethical leadership in explaining the interactive effect of supervisor and employee moral disengagement on employee behaviors. Journal of Business Ethics, 137(4), 731-742. https://doi. org/10.1007/s10551-014-2366-6

Breevaart, K., Bakker, A.B., Demerouti, E., \& Derks, D. (2016). Who takes the lead? A multisource diary study on leadership, work engagement, and job performance. Journal of Organizational Behavior, 37(3), 309-325. https://doi.org/10.1002/job.2041 
Bryant, A., \& Kazan, A.L. (2012). Self-leadership: How to become a more successful, Efficient, and effective leader from the inside out. New York, NY: McGraw Hill Professional.

Coetzer, A., Inma, C., \& Poisat, P. (2017). The job embeddedness turnover relationship. Personnel Review, 46(6), 1070-1088. https://doi.org/10.1108/PR-12-2015-0312

Cole, P. (2017). Talent competition: Missed opportunities as battle intensifies. Crowe Compensation Survey. Retrieved from https://www.bankingexchange.com/news-
feed/item/6696-talent-competition-missed-opportunities-as-battle-intensifies

Fletcher, J.K., \& Kaufer, K. (2003). Shared leadership. In C.L. Pearce \& J.A. Conger (Eds.), Shared leadership: Reframing the how's and why's of leadership (pp. 21-47). Thousand Oakes, CA: Sage.

Fredrickson, B.L. (2001). The role of positive emotions in positive psychology: The broaden-and-build theory of positive emotions. American Psychologist, 56(3), 218-226. https://doi.org/10.1037//0003-066X.56.3.218

Hair, J.F., Celsi, M.W., Ortinau, D.J., \& Bush, R.P. (2008). Essentials of marketing research. New York: McGraw-Hill Higher Education.

Halbesleben, J.R., \& Wheeler, A.R. (2008). The relative roles of engagement and embeddedness in predicting job performance and intention to leave. Journal of Work \& Stress, 22(3), 242-256. https://doi.org/10.1080/02678370802383962

Harunavamwe, M., \& Pillay, D. (2018). The effect of psychological resources on job embeddedness among employees working in the banking sector of the Free State. In 30th Annual Conference of the Southern African Institute of Management Scientists (SAIMS), 8-11 September 2019 (p. 676). Stellenbosch: Stellenbosch University School of Management.

Henseler, J., Ringle, C.M., \& Sinkovics, R.R. (2009). The use of partial least squares path modeling in international marketing. In R.R. Sinkovics \& P.N. Ghauri (Eds.), New challenges to international marketing (pp. 277-319). Bingley: Emerald Group.

Hobfoll, S.E. (2002). Social and psychological resources and adaptation. Review of General Psychology, 6(4), 307-324. https://doi.org/10.1037//1089-2680.6.4.307

Hobfoll, S.E. (2011). Conservation of resource caravans and engaged settings. Journal of occupational and organizational psychology, 84(1), 116-122. https://doi. org/10.1111/j.2044-8325.2010.02016.x

Holtom, B.C., \& Darabi, T. (2018). Job embeddedness theory as a tool for improving employee retention. In Psychology of retention (pp. 95-117). Cham: Springer.

Hom, P.W., Mitchell, T.R., Lee, T.W., \& Griffeth, R.W. (2012). Reviewing employee turnover: Focusing on proximal withdrawal states and an expanded criterion. turnover: Focusing on proximal withdrawal states and an expanded criterio
Psychological Bulletin, 138(5), 831-858. https://doi.org/10.1037/a0027983

Houghton, J.D., Dawley, D., \& DiLiello, T.C. (2012). The abbreviated self-leadership questionnaire (ASLQ): A more concise measure of self-leadership. International Journal of Leadership Studies, 7(2), 216-232.

Jiang, K., Liu, D., McKay, P.F., Lee, T.W., \& Mitchell, T.R. (2012). When and how is job embeddedness predictive of turnover? A meta-analytic investigation. Journal of Applied Psychology, 97(5), 1077-1096. https://doi.org/10.1037/a0028610

Kalla, N.E.E.L.A.M. (2016). Psychological capital: Key to organizational effectiveness, International Journal of Business, Management and Allied Sciences, 3(1), 3013-3018.

Karatepe, O.M. (2016). The effects of organization mission fulfilment and perceived organizational support on job performance: The mediating role of work engagement. International Journal of Bank Marketing, 34(3), 368-387. https:// doi.org/10.1108/IJBM-12-2014-0171

Karatepe, O.M., \& Karadas, G. (2012). The effect of management commitment to service quality on job embeddedness and performance outcomes. Journal of Business Economics and Management, 13(4), 614-636. https://doi.org/10.3846/ 16111699.2011.620159

Khandelwal, P., \& Khanum, F. (2017). Psychological capital: A review of current trends. Indian Journal of Industrial Relations, 53(1), 86-101.

Kotze, M. (2018). The influence of psychological capital, self-leadership, and mindfulness on work engagement. South African Journal of Psychology, 48(2) mindfulness on work engagement. South African Journal
279-292. https://doi.org/10.1177/0081246317705812

Lee, T.W., Mitchell, T.R., Sablynski, C.J., Burton, J.P., \& Holtom, B.C. (2004). The effects of job embeddedness on organizational citizenship, job performance, volitional absences, and voluntary turnover. Academy of Management Journal, 47(5), absences, and voluntary turnover. Academ
711-722. https://doi.org/10.2307/20159613

Lee, H.S., \& Yom, Y.H. (2015). Role of self-leadership and social support in the relationship between job embeddedness and job performance among general hospital Nurses. Journal of Korean Academy of Nursing Administration, 21(4) hospital Nurses. Journal of Korean Academy of Nursing

Lev, S., \& Koslowsky, M. (2012). On-the-job embeddedness as a mediator between conscientiousness and school teachers' contextual performance. European Journal of Work and Organizational Psychology, 21(1), 57-83. https://doi.org/10. Journal of Work and Organizatior
1080/1359432X.2010.535656

Lowry, P.B., \& Gaskin, J. (2014). Partial least squares (PLS) structural equation modeling (SEM) for building and testing behavioral causal theory: When to choose it and how to use it. IEEE transactions on professional communication, 57(2), 123-146. https://doi.org/10.1109/TPC.2014.2312452

Luthans, F., Avolio, B.J., Avey, J.B., \& Norman, S.M. (2007). Positive psychological capital: Measurement and relationship with performance and satisfaction. Personnel Psychology, 60(3), 541-572. https://doi.org/10.1111/j.17446570.2007.00083.x

Luthans, F., Avolio, B.J., Walumbwa, F.O., \& Li, W. (2005). The psychological capital of Chinese workers: Exploring the relationship with performance. Management and Organization Review, 1(2), 249-271. https://doi.org/10.1111/j. 1740-8784.2005.00011.x

Luthans, F., Youssef, C.M., \& Avolio, B.J. (2015). Psychological capital and beyond. Oxford: Oxford University Press.
Malinowski, P., \& Lim, H.J. (2015). Mindfulness at work: Positive affect, hope, and optimism mediate the relationship between dispositional mindfulness, work optimism mediate the relationship between dispositional mindfulness, work
engagement, and well-being. Mindfulness, 6(6), 1250-1262. https://doi. engagement, and well-being.
org/10.1007/s12671-015-0388-5

Mallol, C.M., Holtom, B.C., \& Lee, T.W. (2007). Job embeddedness in a culturally diverse environment. Journal of Business and Psychology, 22(1), 35-44. https:// doi.org/10.1007/s10869-007-9045-x

Mann, A., \& Harter, J. (2016). The worldwide employee engagement crisis [homepage on the Internet]. Gallup. Retrieved from https://www.corporateejournal.com/ Gallup\%202016.pdf

Manz, C.C. (2015). Taking the self-leadership high road: Smooth surface or potholes ahead. Academy of Management Perspectives, 29(1), 132-151. https://doi. org/10.5465/amp.2013.0060

Manz, C.C., \& Neck, C.P. (2004). Mastering self-leadership: Empowering yourself for personal excellence (3rd edn.). Upper Saddle River, NJ: Prentice Hall.

Martin, R. (2008). Beyond personal leader - Member exchange (LMX) quality: The effects of perceived LMX variability on employee reactions. The Leadership Quarterly, 19(1), 20-30. https://doi.org/10.1016/j.leaqua.2007.12.002

Mitchell, T.R., Holtom, B.C., Lee, T.W., Sablynski, C.J., \& Erez, M. (2001). Why people stay: Using job embeddedness to predict voluntary turnover. Academy of Management Journal, 44(6), 1102-1121. https://doi.org/10.5465/3069391

Moses, J., \& Knutsen, T. (2012). Ways of knowing: Competing methodologies in social and political research. London: Macmillan International Higher Education.

Nafei, W. (2015). The role of psychological capital on job embeddedness and organizational cynicism: A study on Menoufia University hospitals. Journal of Management and Sustainability, 5(1), 50-74. 1https://doi.org/10.5539/jms.v5n1p50

Neck, C.P., \& Houghton, J.D. (2006). Two decades of self-leadership theory and research: Past developments, present trends, and future possibilities. Journal of Manageria Psychology, 21(4), 270-295. https://doi.org/10.1108/02683940610663097

Neck, C.P., \& Manz, C.C. (2010). Mastering self-leadership: Empowering yourself for personal excellence. London: Pearson.

Neck, C.P., \& Manz, C.C. (2013). Self-leadership: A cognitive resource for entrepreneurs. Journal of Small Business \& Entrepreneurship, 26(5), 463-480. https://doi.org/10. 1080/08276331.2013.876762

Paek, S., Schuckert, M., Kim, T.T., \& Lee, G. (2015). Why is hospitality employees' psychological capital important? The effects of psychological capital on work engagement and employee morale. International Journal of Hospitality engagement and employee morale. International Journal of Hosk
Management, 50(1), 9-26. https://doi.org/10.1016/j.ijhm.2015.07.001

Pokorny, H. (2013). Portfolios and meaning-making in the assessment of prior learning. International Journal of Lifelong Education, 32(4), 518-534. https://doi. org/10.1080/02601370.2013.778076

Ram, P. (2015). Dimensions of self-leadership in a cross-cultural context. Internationa Journal of Academic Research in Business and Social Sciences, 5(11), 59-77. https://doi.org/10.6007/IJARBSS/v5-i11/1893

Rego, A., Sousa, F., Marques, C., \& eCunha, M.P. (2012). Authentic leadership promoting employees' psychological capital and creativity. Journal of Busines Research, 65(3), 429-437. https://doi.org/10.1016/j.jbusres.2011.10.003

Ringle, C.M., Wende, S., \& Becker, J.M. (2015). SmartPLS 3. Boenningstedt: SmartPLS $\mathrm{GmbH}$. Retrieved from http://www.smartpls.com.

Salman, A., Ahmad, N., \& Matin, F. (2014). Factors affecting on employees' retention in banking sector: An investigation from Karachi. European Journal of Business and Management, 6(37), 2222-2839.

Sekiguchi, T., Burton, J.P., \& Sablynski, C.J. (2008). The role of job embeddedness on employee performance: The interactive effects with leader - Member exchange and organization-based self-esteem. Personnel Psychology, 61(4), 761-792. https://doi.org/10.1111/j.1744-6570.2008.00130.x

Sun, T., Zhao, X.W., Yang, L.B., \& Fan, L.H. (2012). The impact of psychological capital on job embeddedness and job performance among nurses: A structural equation
approach. Journal of Advanced Nursing, 68(1), 69-79. https://doi.org/10.1111/ approach. Journal of Advance
j.1365-2648.2011.05715.x

Swider, B.W., Boswell, W.R., \& Zimmerman, R.D. (2011). Examining the job searchturnover relationship: The role of embeddedness, job satisfaction, and available alternatives. Journal of Applied Psychology, 96(2), 432-441. https://doi. org/10.1037/a0021676

Van Zyl, E., Dalglish, C., Du Plessis, M., Lues, L., Pietersen, E., Ngunjiri, F., \& Kablan. P. (2016). Leadership in the African context. Cape Town: Juta.

Van Zyl, E.V. (2013). Self-leadership and happiness within the African working context. Journal of Psychology, 4(2), 59-66. https://doi.org/10.1080/09764224.2013.11885494

Yakın, M., \& Erdil, O. (2012). Relationships between self-efficacy and work engagement and the effects on job satisfaction: A survey on certified public accountants. Procedia-Social and Behavioral Sciences, 58(1), 370-378. https://doi.org/10.1016/ j.sbspro.2012.09.1013

Yao, X., Lee, T.W., Mitchell, T.R., Burton, J.P., \& Sablynski, C.S. (2004). Job embeddedness: Current research and future directions. In R. Griffeth \& P. Hom (Eds.), Innovative theory and empirical research on employee turnover (pp. 153-187). Charlotte, NC: Information Age Publishing.

Yavas, U., Babakus, E., \& Karatepe, O.M. (2008). The effects of job demands, job resources and intrinsic motivation on emotional exhaustion and turnover intentions: A study in the Turkish hotel industry. International Journal of Hospitality \& Tourism Administration, 9(4), 384-404. https://doi.org/10.1080/15256480802427339

Zhao, E., \& Liu, L. (2010). Comments on development of job embeddedness about study on turnover and exploration into application in enterprises. Asian Social Science, 7(6), 63-70. https://doi.org/10.5539/ass.v6n6p63 